\title{
Analysis of the Contribution Rate of Climate Change and Anthropogenic Activity to Runoff Variation in Nenjiang Basin, China
}

\author{
Liqin Dong ${ }^{1,2, *}$, Guangxin Zhang ${ }^{2}$, Xiping Cheng ${ }^{1}$ and Yanfang Wang ${ }^{1}$ \\ 1 School of Geography, Southwest Forest University, Kunming 650224, China; \\ xipingcheng2012@163.com (X.C.); dlq2008@126.com (Y.W.) \\ 2 Key Laboratory of Wetland Ecology and Environment, Northeast Institute of Geography and Agroecology, \\ Chinese Academy of Sciences, Changchun 130012, China; zhangguangxin03@163.com \\ * Correspondence: dongliqin2013@163.com; Tel.: +86-135-2927-5696
}

Received: 2 November 2017; Accepted: 1 December 2017; Published: 4 December 2017

\begin{abstract}
The Pettitt abrupt change test method based on ArcGIS was used to undertake change-point analysis on climatic (precipitation and potential evapotranspiration; 39 meteorological stations) and runoff data (27 hydrological stations) from 1954-2015 in the Nenjiang basin. The hydrological sensitivity analysis method was also used to calculate the influential component of climate change upstream, mid-stream, and downstream of the Nenjiang basin, as well as the effect of anthropogenic activities on runoff. Our results show that the upstream area has the highest contribution rate of climate change, followed by the mid-stream area; the downstream area has the lowest contribution rate. Studying climate change contribution rates in various sites in the Nenjiang basin, in addition to anthropogenic activities affecting runoff, can provide the foundation for the protection and utilization of basin water resources, as well as the conservation and restoration of wetlands.
\end{abstract}

Keywords: Nenjiang basin; climate change; runoff; contribution rate

\section{Introduction}

In relation to global warming, the effect climate change has on hydrological processes and water resources of basins has become an important research area [1,2]. The large-scale utilization of water resources by intensive anthropogenic activities has resulted in significant changes to surface runoff. With the continued effects of global warming, investigating the evolution pattern of water resources impacted by natural changes and human activities has become a new and important research area in water science [3].

The northeastern region was characterized by frequent droughts and floods, and experienced a severe issue of scarce water resources [4]. The Nenjiang river basin is located in the midwestern part of the northeastern region of China, an area that has developed water systems and an abundance of developed wetlands, such as lacustrine and swamps. This area is also important as it regulates natural water reserves and the regional water balance, as well as providing ecological protection to prevent desertification in the western Songnen Plain expanding towards the middle-eastern areas [5-7]. Due to the impact of climate change, as well as over-exploitation and utilization by the local population, the Nenjiang river basin and its internal wetlands have faced multiple problems during recent decades, resulting in the shrinking of the wetland area and degrading functions. At the same time, the flood-regulating function of wetlands have drastically declined, leading to increased potential threats to water security and to people's livelihood and property security.

In this paper, by analyzing the meteorological and hydrological data of the Nenjiang river basin, the change point is determined and hydrological sensitivity analysis method is used to calculate the 
contribution rate of climate change and human activities to runoff in the upper, middle, and lower reaches of Nenjiang river basin. It is important for water resource utilization and wetland conservation in the Nenjiang river basin.

\section{Methods}

\subsection{Data Source and Processing}

Meteorological data spanning 1954-2015 was obtained from 39 meteorological stations in the local area to study climate change characteristics in the Nenjiang watershed (Figure 1); 19 stations were located within the watershed and 20 surrounded the watershed. Missing observation records from 1954-1960 from some stations (for example Huma, Ergun River, Tulihe River, and Heihe River) were filled through interpolation.

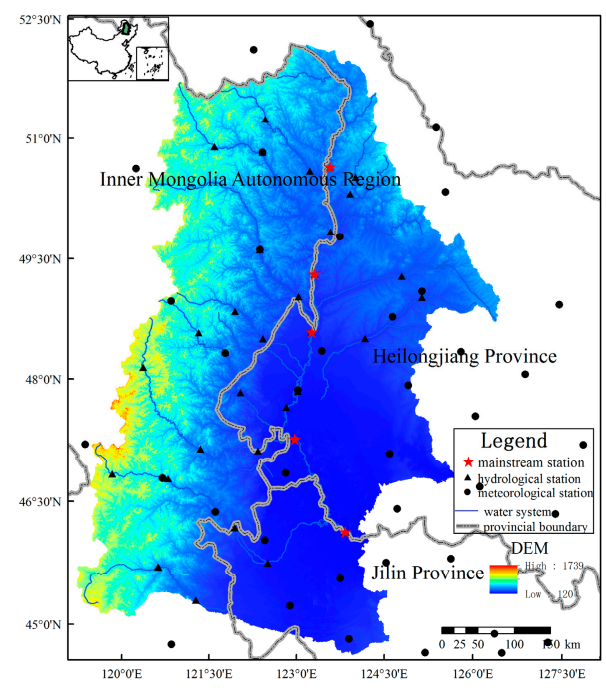

Figure 1. Location of the study area, and distribution of hydrological and meteorological stations.

Hydrological data was obtained from 27 hydrological stations located in cities and provinces surrounding the watershed. After omitting stations that did not have long-term data, or contained relatively shorter time series, we selected the monthly runoff materials of five mainstream stations (Shihuiyao station, Ayanqian station, Tongmeng station, Jiangqiao station, and Dalai station), and monthly measured data from 22 branch stations, such as Liujiatun station, Xiaoergou station, and Zhalantun station. Data obtained from the hydrological stations were used for watershed runoff analysis and flood analysis.

\subsection{Data Analysis}

Based on ArcGIS desktop tools, and according to the distribution of meteorological stations in the Nenjiang watershed, we selected the method of interpolating Thiessen polygons inside discrete observation data points to conduct spatial interpolation analysis for temperature, precipitation, and evapotranspiration trends of change across the watershed. The perennial surface temperature, surface precipitation, and surface potential evapotranspiration of the Nenjiang watershed were calculated and their annual series were linearly fitted. The Mann-Kendall trend test method was adopted for the spatial significant test of temperature and precipitation $(\alpha<0.05)$.

(1) The Mann-Kendall (M-K) non-parametric test analyzes data trends by calculating the sums of ranks of time series and comparing the relative order of magnitude [6]. We utilized the M-K method to carry out a change-point analysis of mean values under different types of runoff from 
the monitoring stations in the Nenjiang basin. Results from this analysis enabled us to discuss characteristics of basin runoff evolution.

The M-K method was based on a stable climate sequence, and was defined as:

$$
S_{K}=\sum_{i=1}^{k} m_{i}(4 \leq k \leq n)
$$

where $m_{i}$ denotes the cumulative amount when the sample $x_{i}>x_{j}(2 \leq j \leq i)$. Under the assumption that the time series was randomly independent, it can be defined as:

$$
U F_{k}=\frac{S_{k}-E_{(s k)}}{\sqrt{\operatorname{Var}\left(S_{k}\right)}}(1 \leq k \leq n)
$$

In the equation, $U F_{k}$ is the standard normal distribution; at a given significant level, if the $U F_{k}$ value was greater than 0 , it indicated that the series presented a rising trend, otherwise, it presented a declined trend. If $\left|U F_{k}\right|>U_{a / 2}$, this indicated that there existed a significant trend change in the series. When $\alpha=0.05, U_{a / 2}=1.96$.

(2) The statistical abrupt change test method: numerous abrupt change detection methods have been used with time series data [7,8], among which Pettitt's abrupt change detection method is a non-parametric test method widely used for detecting change points in a hydrological series [9]. In this study, we adopted Pettitt's method to detect abrupt change phenomena in precipitation, evapotranspiration, and runoff in long-term time series data in the Nenjiang watershed. This method not only identifies the location and amount of change points; it can also determine whether the change points are statistically significant.

The null hypothesis $H_{0}$ of the Pettitt abrupt change detection method is that change points do not exist in the series. If the moment $t$ meets the following conditions:

$$
k_{t}=\operatorname{Max}\left|U_{t, n}\right|, \quad 1 \leq t \leq n
$$

where $U_{t, n}$ will generate new series based on the frequency that the first sample series exceed the second sample series, then point $t$ will be considered as a change point. Meanwhile, the following statistics will be calculated:

$$
P=2 \exp \left\{-6\left(k_{n}\right)^{2} /\left(n^{3}+n^{2}\right)\right\}
$$

If $P \leq 0.05$, the detected change points will be considered as statistically significant.

In order to test the detected results from the Pettitt abrupt change method, a precipitation-runoff double cumulative curve (DCC) was used to verify upstream, mid-stream, and downstream areas of the Nenjiang watershed. The equations used were:

$$
\begin{gathered}
S_{P_{i}}=\sum_{i=1}^{i} P_{i} \\
S_{R_{i}}=\sum_{i=1}^{i} R_{i}
\end{gathered}
$$

where $S_{R_{i}}$ denotes the cumulative measured runoff of the preceding $i$ years; $S_{P_{i}}$ is the cumulative measured precipitation of the preceding $i$ years; $P_{i}$ is the precipitation of the $i$ th year; and $R_{i}$ is the runoff of the $i$ th year.

Usually, periods without anthropogenic disturbance result in a straight line for DCC. However, when anthropogenic activities directly or indirectly impose effects on underlying surfaces, 
the DCC will shift and the location of offset points will also be the time when anthropogenic activities intensified [10].

(3) The hydrological sensitivity analysis method: this method is used to analyze the percentage change of annual runoff with changes in annual mean precipitation and potential evapotranspiration [11]. This method can also be used to distinguish the contributions of climate change and anthropogenic activities to runoff change.

For a natural closed watershed, its water balance can be represented with the following equation:

$$
P=E+Q+\Delta S
$$

where $P$ denotes precipitation; $E$ denotes evapotranspiration; $Q$ denotes surface runoff; and $\Delta S$ denotes the change of watershed water storage. For the long-term water equilibrium of a watershed (for example, 10 years or longer), $\Delta S$ can be considered to be close to 0 , and the following relationship exists between long-term annual mean evapotranspiration, as well as precipitation and potential evapotranspiration:

$$
\frac{E}{P}=\frac{1+w\left(E_{0} / P\right)}{1+w\left(E_{0} / P\right)+\left(E_{0} / P\right)^{-1}}
$$

where $w$ denotes the water availability coefficient of vegetation, which represents the relative variance of soil water utilization by different vegetation types. This can be obtained through the optimization of Equations (7) and (8).

Dooge et al. [12] believed that changes of precipitation and potential evapotranspiration can result in the change of the water equilibrium of a watershed. For a specific watershed, the change in runoff is a result of the combination of the effects of climate change and anthropogenic activities. Here, we assumed that runoff change is the sum of the variation component induced by climate change and the variation component induced by anthropogenic activity. According to the hydrological sensitivity relationship, the variation of annual mean runoff induced by climate change can be expressed by the following equation [13]:

$$
\begin{gathered}
\Delta Q_{\text {climate }}=\beta \Delta P+\gamma \Delta E_{0} \\
\Delta Q_{\text {total }}=\Delta Q_{\text {climate }}+\Delta Q_{\text {human }}
\end{gathered}
$$

where $\Delta Q_{\text {total }}, \Delta Q_{\text {climate }}$, and $\Delta Q_{\text {human }}$ denote the change of measured runoff, the contributions of climate change, and the contributions of human activities to runoff change, respectively; $\Delta P$ and $\Delta E_{0}$ represent the change of precipitation and potential evapotranspiration, respectively; and $\beta$ and $\gamma$ denote the sensitivity parameters of runoff to precipitation and potential evapotranspiration, which can be calculated by the following equations [13]:

$$
\begin{gathered}
\beta=\frac{1+2 x+3 w x}{\left(1+x+w x^{2}\right)^{2}} \\
\gamma=-\frac{1+2 w x}{\left(1+x+w x^{2}\right)^{2}}
\end{gathered}
$$

where $x$ denotes the aridity coefficient, i.e., $E_{0} / P$.

\section{Results}

\subsection{Abrupt Change Analysis of Annual Runoff Series}

The Pettitt abrupt change detection method was used to conduct the change-point analysis of precipitation, potential evapotranspiration, and runoff in the Nenjiang watershed, 1956-2015. 
Results show that the changing rate of perennial mean precipitation and runoff were $-5 \mathrm{~mm} / 10 \mathrm{a}$ and $-8.6 \mathrm{~mm} / 10 \mathrm{a}$, respectively, and that the changes were significant (Table 1). The Mann-Kendall test result showed that the test value of perennial mean runoff was $|U|>1.96$, indicating that it had a relatively strong decreasing trend at the significance level of $\alpha=0.05$. The change of perennial mean potential evapotranspiration was not significant. The Pettitt abrupt change test of perennial mean runoff showed that there were two points of change between 1956 and 2015, these being in 1974 and 1981.

Table 1. Pettitt change point analysis of annual precipitation, potential evapotranspiration, and runoff in the Nenjiang River basin.

\begin{tabular}{cccccc}
\hline \multirow{2}{*}{ Factor } & Mean (mm/a) & $\begin{array}{c}\text { Change Rate } \\
(\mathbf{m m} / \mathbf{1 0 a})\end{array}$ & \multicolumn{2}{c}{ Mann-Kendall Test } & $\begin{array}{c}\text { Pettitt Abrupt } \\
\text { Change Detection }\end{array}$ \\
\cline { 4 - 4 } & & $\mathbf{U}$ & Significance & \\
Precipitation & 506.8 & -5.2 & -1.12 & - & - \\
Evapotranspiration & 948.8 & 0.9 & 0.01 & - & - \\
Runoff & 167.3 & -7.8 & -2.26 & 0.99 & 1974,1981 \\
\hline
\end{tabular}

In order to verify the accuracy of the Pettitt test, the precipitation-runoff DCCs based on annual mean precipitation and annual mean runoff for the upstream, mid-stream, and downstream areas in the Nenjiang watershed were plotted (Figure 2).

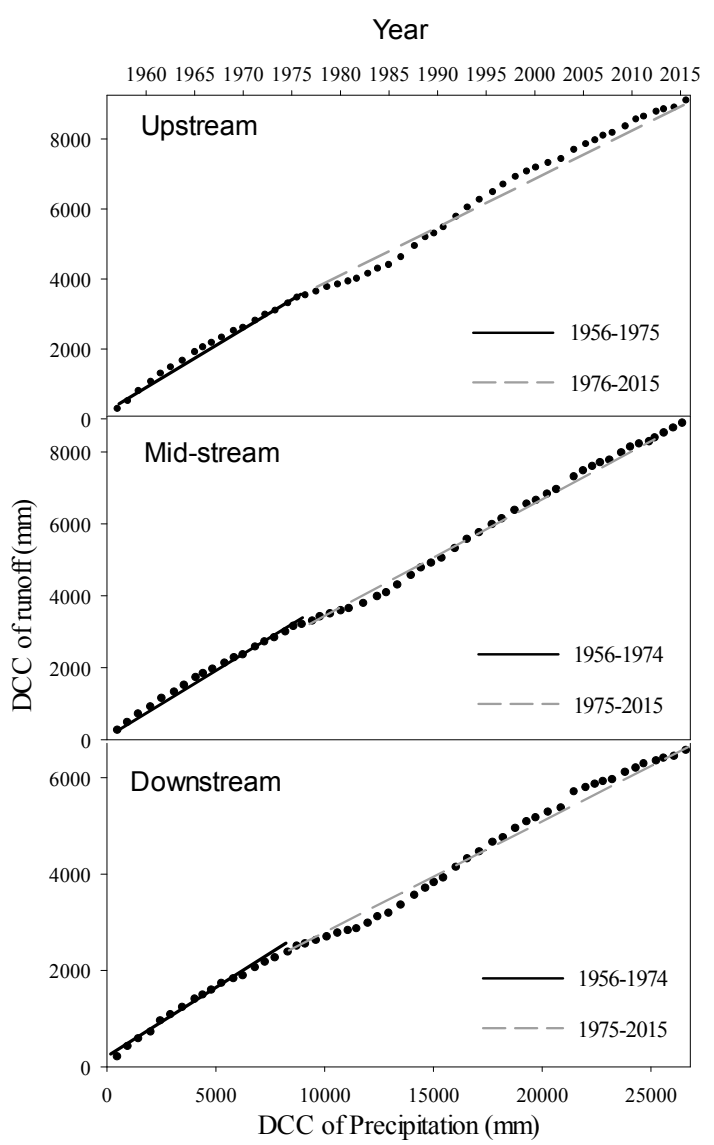

Figure 2. DCC (precipitation-runoff double cumulative curve) of rainfall-runoff in the upper, middle, and lower reaches of the Nenjiang River basin.

Results show that the first evident shift in the upstream area occurred in 1975, and the first evident shift in the mid-stream and downstream areas both occurred in 1974. By using the 
Mann-Kenall test, c. 1980 was determined as the year when whole-watershed runoff increased, and the offset point of the precipitation-runoff DCC was prior to 1980. The period before 1974 can be considered as the "natural baseline year" without anthropogenic disturbance, and 1975-2015 can be considered as the "impact stage of human activity".

\subsection{The Rate of Contribution of Climate Change and Anthropogenic Activities to Runoff}

The change of watershed runoff was a result of the combined effects of climate change and anthropogenic activities. The upstream, mid-stream, and downstream areas of the Nenjiang watershed were uniformly classified into the natural base year period of 1956-1974 and impact stages of anthropogenic activity periods of 1975-1989, 1990-1999, and 2000-2015. Precipitation, potential evapotranspiration, and measured runoff for each period were statistically analyzed (Table 2). It was found that the changing trend of precipitation across the whole watershed was not consistent; an obvious trend of increase was noted from 1990 to 1999 and a severe decrease occurred from 2000 to 2015. Potential evapotranspiration in the upstream, mid-stream, and downstream areas all showed increasing trends, whilst runoff during the periods of 1975-1989 and 2000-2015 showed a declining trend; from 19901999 a decreasing trend in the upstream and an increasing trend in both the mid-stream and downstream areas were recorded.

Table 2. Changes of precipitation, potential evapotranspiration, and observed runoff in the Nenjiang River basin.

\begin{tabular}{|c|c|c|c|c|c|c|c|}
\hline \multirow{2}{*}{ Region } & \multirow{2}{*}{ Period } & \multicolumn{2}{|c|}{$\Delta P$} & \multicolumn{2}{|c|}{$\Delta E T_{0}$} & \multicolumn{2}{|c|}{$\Delta Q$} \\
\hline & & $\mathbf{m m} / \mathbf{a}$ & $\%$ & $\mathbf{m m} / \mathbf{a}$ & $\%$ & $\mathrm{~mm} / \mathrm{a}$ & $\%$ \\
\hline \multirow{3}{*}{ Upstream } & 1975-1989 & -20.7 & -4.4 & 28.9 & 4.3 & -17.7 & -9.6 \\
\hline & 1990-1999 & 16.5 & 3.5 & 52.1 & 7.7 & -4 & -2.2 \\
\hline & 2000-2015 & -66.8 & -12.9 & 68.8 & 9.8 & -58.4 & -30.9 \\
\hline \multirow{3}{*}{ Mid-stream } & 1975-1989 & -4.5 & -1.0 & 38.1 & 5.1 & -10.5 & -5.7 \\
\hline & 1990-1999 & 34.6 & 7.3 & 7.8 & 1.0 & 22.8 & 13.6 \\
\hline & 2000-2015 & -36.3 & -7.8 & 63.6 & 7.9 & -51 & -29.8 \\
\hline \multirow{3}{*}{ Downstream } & 1975-1989 & 39.9 & 8.5 & 17.3 & 1.7 & -16.3 & -12.2 \\
\hline & 1990-1999 & 13.5 & 2.9 & 15.3 & 1.5 & 13.9 & 10.4 \\
\hline & 2000-2015 & -77.8 & -16.3 & 15.8 & 1.5 & -28.1 & -21.1 \\
\hline
\end{tabular}

By adopting the hydrological sensitivity analysis method proposed by Milly et al. [14], a method based on runoff change induced by precipitation and potential evapotranspiration, we calculated the influencing component of climate change and anthropogenic activities to runoff upstream, mid-stream, and downstream in the Nenjiang watershed. Results from this analysis (Table 3) showed that influencing components of climate change and anthropogenic activities on runoff differed greatly during different periods across the watershed. 
Table 3. The effect of climate change and human activities on runoff.

\begin{tabular}{|c|c|c|c|c|c|c|c|c|}
\hline \multirow{2}{*}{ Region } & \multirow{2}{*}{ Period } & \multirow{2}{*}{$\begin{array}{c}\text { Precipitation } \\
\mathrm{mm}\end{array}$} & \multirow{2}{*}{$\begin{array}{l}E T_{0} \\
\mathrm{~mm}\end{array}$} & \multirow{2}{*}{$\frac{\Delta Q_{\text {total }}}{\mathrm{mm}}$} & \multicolumn{2}{|c|}{$\Delta Q_{\text {climate }}$} & \multicolumn{2}{|c|}{$\Delta Q_{h u m a n}$} \\
\hline & & & & & $\mathbf{m m}$ & $\%$ & $\mathrm{~mm}$ & $\%$ \\
\hline \multirow{5}{*}{ Upstream } & 1956-1974 & 475.2 & 676.6 & - & - & - & - & - \\
\hline & 1975-1989 & 454.5 & 705.5 & -17.7 & -16.1 & 90.8 & -1.6 & 9.2 \\
\hline & 1990-1999 & 491.7 & 728.7 & -4 & -3.3 & 82.8 & -0.7 & 17.2 \\
\hline & 2000-2015 & 465.0 & 816.2 & -52.8 & -43.9 & 72.4 & -16.7 & 27.6 \\
\hline & 1975-2015 & 470.4 & 750.1 & -28.4 & -21.1 & 82.0 & -6.3 & 18.0 \\
\hline \multirow{5}{*}{ Mid-stream } & 1956-1974 & 472.1 & 749.6 & - & - & - & - & - \\
\hline & 1975-1989 & 467.6 & 787.7 & -10.5 & -8.6 & 82.3 & -1.9 & 17.7 \\
\hline & 1990-1999 & 506.7 & 757.4 & 22.8 & 17.9 & 78.3 & 4.9 & 22.8 \\
\hline & 2000-2015 & 457.0 & 827.3 & -55.9 & -31.2 & 58.3 & -21.4 & 41.7 \\
\hline & 1975-2015 & 477.1 & 798.3 & -14.8 & -10.7 & 74.1 & -3.1 & 25.9 \\
\hline \multirow{5}{*}{ Downstream } & 1956-1974 & 468.2 & 1002.3 & - & - & - & - & - \\
\hline & 1975-1989 & 508.1 & 1019.6 & -16.3 & -13.3 & 81.8 & -3 & 18.2 \\
\hline & 1990-1999 & 481.7 & 987 & 13.9 & 8.5 & 61.1 & 5.4 & 38.9 \\
\hline & 2000-2015 & 448.6 & 1031.5 & -32.5 & 22.8 & 67.8 & -9.3 & 32.2 \\
\hline & $1975-2015$ & 479.5 & 1025.8 & -12.8 & -9.3 & 71.1 & -4.2 & 28.9 \\
\hline
\end{tabular}

From the perspective of different periods, between 1975-1989 and 1990-1999, the rate of contribution of climate change to runoff change were greatest in the upstream area, followed by the mid-stream and downstream (this being the smallest) areas. From 2000 to 2015, the rate of contribution of climate change to runoff change was greatest in the upstream and downstream areas, but smallest in the mid-stream area. From 1975 to 2015, the area most influenced by climate change was the upstream area, with contribution rates as high as $82.0 \%$, followed by $74.1 \%$ for the mid-stream area and $71.1 \%$ for the downstream area. The different influencing components of climate change on runoff in the different areas clearly shows the internal difference in climate change in different areas, which in turn generates feedbacks on runoff change. Anthropogenic activities had an effect of negative flow reduction on runoff. Based on different degrees of exploitation and utilization of water resources, runoff losses were also different, among which the decrease in runoff losses upstream were the largest. According to the contribution of anthropogenic activities to runoff change, it was largest in the downstream area with a contribution rate of $28.9 \%$, followed by mid-stream and upstream areas, which were $25.9 \%$ and $18.0 \%$, respectively.

\section{Conclusions and Discussion}

From the perspective of the whole Nenjiang watershed, watershed runoff was jointly affected by climate change and anthropogenic activities, and the percentage of climate change effect was relatively large, being as high as $71.1-82.0 \%$. From the perspective of different areas in the Nenjiang watershed, the upstream area was located in a mountainous area, which had the least anthropogenic activity $(18 \%)$; the downstream area is located in agricultural areas of the Songnen Plain and was most affected by anthropogenic activities (28.9\%). From the perspective of different periods, it was seen that after the year 2000, the contribution rate of climate change to runoff variation was the greatest. This difference occurred for two reasons: one is that the upstream area is in the mountain area, with fewer human activities, and the downstream area is the Songnen Plain, with more agricultural activities; the other reason is that since the 1990s, with rapid economic development, fast population growth, increase in the planting area for agricultural products, and the construction of water conservancy project facilities, human activities have had an increasing impact on runoff changes. Currently, most studies are concentrated on the influence of climate changes on the hydrological situation of the basin, such as research on Himalayan region [15], or distinguishing the climate factors (atmospheric temperature, rainfall) and quantifying the contribution rate of each climate factor to the influence over runoff [16]. Some researchers also cover the contribution of climate change and human activities to basin runoff, 
although with the focus mainly on the whole basin or the upstream area $[17,18]$, fewer research and comparisons are carried out on upstream, mid-stream, and downstream areas. There is a big difference between the methods of the studies, but each method has its own limits. The method we chose was the hydrological sensitivity analysis method, which was analyzed and calculated based on the period of the natural baseline year. However, this baseline year was, to some extent, influenced by anthropogenic activities and errors may therefore exist. It is therefore important for future investigations calculating the contribution rates of climate change and anthropogenic activities to runoff to omit the effects of anthropogenic activities on the period of the natural baseline year, thereby increasing accuracy.

Factors influencing runoff are complex; however, the main consideration in this study is precipitation and evapotranspiration. With gradual technological developments, an advancement of scientific methods in hydrological time series analysis, and the introduction of impacting factors in the hydrological cycle, such as land use and underlying surface properties, analysis of runoff evolution patterns, and attribute analysis, will advance. Based on China's national conditions, time series analysis of hydrological field data is relatively short. If a region with abundant datasets, similar climate, and underlying surface conditions can be taken as a reference basin, it will then be possible to undertake long-term, in-depth analyses.

By analyzing the contribution rates of climate change and anthropogenic activities to runoff in different periods and in different areas in the Nenjiang watershed since the 1970s, we can not only explore its temporal and spatial changing pattern, but also provide guidance for policy-makers regarding local water resource conservation and utilization.

Acknowledgments: This work was funded by the National Natural Science Foundation of China (Grant 41461022), and the National Key Research and Development Program of China (Grant 2010CB428404). We are very grateful to the editors and anonymous reviewers for their valuable comments, which greatly improved the quality of the paper.

Author Contributions: Liqin Dong conducted the simulation and wrote the paper. Guangxin Zhang designed the assessment framework and help modify the paper. Xiping Cheng helped designed the assessment framework and results discussions. Yanfang Wang provided technical supports on impact assessments.

Conflicts of Interest: The authors declare no conflict of interest.

\section{References}

1. Beniston, M. Climatic Chanage: Implications for the Hydrological cycle and for Water Management; Kluwer Academic Publishers: Dordrecht, The Netherlands, 2002.

2. Stocker, T.F.; Raible, C.C. Water cycle shifts gear. Nature 2005, 434, 830-832. [CrossRef] [PubMed]

3. Intergovernmental Panel on Climate Change (IPCC). Climate Change 2014: Synthesis Report; Contribution of Working Groups I, II and III to the Fifth Assessment Report of the Intergovernmental Panel on Climate Change; IPCC: Geneva, Switzerland, 2014.

4. $\quad$ Liang, F.; Liu, D.D.; Wang, W.Z.; Zhang, F.R.; Yu, F.J. Temporal and spatial variability of summer extreme precipitation events in Northeast China during 1961-2013. Arid Land Geogr. 2016, 39, 565-572. (In Chinese)

5. Liu, Y.; Sheng, L.; Liu, J. Impact of Wetland Change on Local Climate in Semi-arid Zone of Nor-theast China. Chin. Geogr. Sci. 2015, 25, 309-320. [CrossRef]

6. Khaled, H.; Hamed, A.; Rao, R. A modified Mann-Kendall Trend test for Auto correlated data. J. Hydrol. 1998, 204, 182-196.

7. Kundzewiez, Z.W.; Robson, A.J. Change detection in hydrological records-A review of the methodology. Hydrol. Sci. J. 2004, 49, 7-19. [CrossRef]

8. Zhang, Y.H.; Song, X.F. Techniques of abrupt change detection and trends analysis in hydroclimatic time-series: Advances and evaluation. Arid Land Geogr. 2015, 38, 652-661. (In Chinese)

9. Pettitt, A.N. A non-parametric approach to the change-point problem. Appl. Stat. 1979, 28, 126-135. [CrossRef]

10. European Commission. Vulnerability and Risk Mapping for the Protection of Carbonate Aquifers: Final Report COST Action 620; European Commission: Brussels, Belgium, 2004. 
11. Jones, R.N.; Chiew, F.H.S.; Boughtom, W.C.; Zhang, L. Estimating the sensitivity of mean annual runoff to climate change using selected hydrological models. Adv. Water Resour. 2006, 29, 1419-1429. [CrossRef]

12. Dooge, J.C.I.; Bruen, M.; Parmentier, B. A simple model for estimating the sensitivity of runoff to long-term changes in precipitation without a change in vegetation. Adv. Water Resour. 1999, 23, 153-163. [CrossRef]

13. Li, L.J.; Zhang, H.; Wang, H.; Wang, J.; Yang, J.W.; Jiang, D.J.; Qin, D.Y. Assessing the impact of climate change and human activities on streamflow from the Wuding River basin in China. Hydrol. Process. 2007, 21, 3485-3491. [CrossRef]

14. Milly, P.C.D.; Dunne, K.A. Macro-scale water fluxes2. Water and energy supply control of their inter-annual variability. Water Resour. Res. 2002, 38, 1206. [CrossRef]

15. Nepal, S. Impacts of climate change on the hydrological regime of the Koshi river basin in the Himalayan region. J. Hydro-Environ. Res. 2016, 10, 76-89. [CrossRef]

16. Li, B.; Chen, Y.; Xiong, H. Quantitatively evaluating the effects of climate factors on runoff change for Aksu River in northwestern China. Theor. Appl. Climatol. 2016, 123, 97-105. [CrossRef]

17. Peng, D.; Qiu, L.; Fang, J.; Zhang, Z. Quantification of climate changes and human activities that impact runoff in the Taihu Lake Basin, China. Math. Probl. Eng. 2016, 2016, 2194196. [CrossRef]

18. Li, Y.; He, D.; Li, X.; Zhang, Y.; Yang, L. Contribution of climate variability and human activities to runoff changes in the upper catchment of the Red River Basin, China. Water 2016, 8, 414. [CrossRef]

(C) 2017 by the authors. Licensee MDPI, Basel, Switzerland. This article is an open access article distributed under the terms and conditions of the Creative Commons Attribution (CC BY) license (http://creativecommons.org/licenses/by/4.0/). 